\title{
Kidney Synovial Sarcoma
}

National Cancer Institute

\section{Source}

National Cancer Institute. Kidney Synovial Sarcoma. NCI Thesaurus. Code C157737.

A synovial sarcoma arising from the kidney. 